\title{
Prevalence and Predictors of Potentially Inappropriate Medication Prescription Among Older Adults: A Cross-Sectional Study in the State of Qatar
}

\author{
Ayman AI-Dahshan ${ }^{1}$ D $\cdot$ Vahe Kehyayan $^{2}$
}

Accepted: 30 October 2020 / Published online: 17 November 2020

(c) The Author(s) 2020

\begin{abstract}
Background Potentially inappropriate medications (PIMs) often lead to sub-optimal or poor health outcomes in older adults. Objective The objective of this study was to determine the prevalence and predictors of PIM prescription among older adults in Qatar.

Patients and Methods This was a cross-sectional, retrospective study using data from the electronic medical records of Qatari patients (age $\geq 65$ years) attending the 23 primary healthcare (PHC) centers in Qatar from April 1, 2017 to September 30, 2017. PIMs were identified based on the Beers 2015 criteria: (1) medications to avoid for many or most older adults, and (2) medications to be used with caution in older adults. Descriptive statistics were used to estimate the prevalence of PIM prescription; multivariable logistic regression analysis was performed to identify predictors of PIM prescription among the study population.

Results 5639 older adults were included with a mean age of $72.8( \pm 6.5)$ years; $53.8 \%$ were females. The prevalence of PIMs that should be avoided was $60.7 \%$, with the most prevalent ones being gastrointestinal (84.2\%), pain (49.9\%), and central nervous system (10.4\%) drugs. Most patients (61.1\%) were prescribed one PIM, 26.9\% two PIMs, and 12.0\% three or more PIMs. The prevalence of PIMs that should be used with caution was 40.6\%, with diuretics (83.1\%), antidepressants (25.7\%), and antiplatelets (18.3\%) as the most prevalent drug classes. Multivariable logistic regression showed female gender, polypharmacy, and certain comorbidities to be significant predictors of PIM prescription.

Conclusions Older adults attending Qatar's 23 PHC centers are prescribed a high number of PIMs. Because of the high risk of PIM prescription, the practice of medication reconciliation should be strengthened and reinforced.
\end{abstract}

\section{Introduction}

Potentially inappropriate medications (PIMs) are classes of drugs whose risks may potentially outweigh their benefits [1]. Despite evidence of negative outcomes in older adults,

Electronic supplementary material The online version of this article (https://doi.org/10.1007/s40801-020-00220-9) contains supplementary material, which is available to authorized users.

Ayman Al-Dahshan

ayman.aldahshan@hotmail.com

Vahe Kehyayan

vkehyaya@ucalgary.ca

1 Community Medicine Residency Program, Department of Medical Education, Hamad Medical Corporation, Doha, Qatar

2 University of Calgary in Qatar, Doha, Qatar

\section{Key Points}

The prevalence of potentially inappropriate medications (PIMs) prescription among Qatari older adult patients attending primary healthcare (PHC) centers was high.

The most prevalent classes of PIMs that should be avoided were gastrointestinal, pain, and central nervous system drugs. While diuretics, antidepressants, and antiplatelets were the most prevalent classes of PIMs that should be used with caution.

Female sex, polypharmacy, diabetes mellitus, hypertension, cardiovascular disease, asthma, gastroesophageal reflux disease, and arthritis were significant predictors of higher PIM prescription. 
healthcare practitioners continue to prescribe PIMs [2] to the extent that it has now become a public health concern because of its association with increased morbidity, hospitalization, and mortality [3-6]. The prevalence of PIM use in older adult populations in both developed and developing countries is very high. High prevalence of PIM prescription has been shown in several countries like Sweden [7], Ireland [8], and the United States [1]. The high prevalence of PIM use in Middle Eastern countries has also been a concern [9-13].

Research has also identified the most common medications prescribed, including anti-hypertensive drugs [12]; benzodiazepines and nonsteroidal anti-inflammatory drugs [14]; and gastrointestinal and endocrine agents [10]. Further classes of commonly prescribed PIMs include antipsychotics and selective serotonin reuptake inhibitors [11], and pain medications and antispasmodics [9]. Several factors have been associated with PIM prescription in older adults. These include increasing age [15], polypharmacy [1, 10, 16, 17], female gender $[1,9,17,18]$, dependence on instrumental activities of daily living [19], and frailty and cognitive impairments [20]. Other factors also include certain chronic comorbidities such as hypertension, diabetes mellitus, cardiovascular disease, and mental health conditions [11].

Several approaches have been used to classify PIMs. In the early 1990s, Beers and colleagues in the USA developed lists of PIMs for older adults with updates in subsequent years [21]. The Beers criteria were developed as a strategy to reduce negative health outcomes in older adults. The 2015 Beers criteria included (1) medications to avoid for many or most older adults; (2) medication classes to avoid in older adults with certain diseases and syndromes; (3) medications to be used with caution in older adults; (4) drugs for which dose adjustment is required based on kidney function; and (5) drug-drug interactions [21, 22].

The aim of this study was to determine the prevalence and predictors of PIM prescription in older adults attending primary healthcare (PHC) centers in Qatar according to the 2015 Beers criteria.

\section{Analytical and Conceptual Framework}

To identify variables associated with PIM prescriptions, we adopted Andersen's Behavioral Model for health service use as a theoretical framework. In our study, we defined health service use as patients' access to prescription medications at any of Qatar's 23 PHC centers. This framework proposes that an individual's health service utilization is influenced by three categories of factors: predisposing factors (e.g., age, gender), enabling factors (e.g., employment, distance to health service), and need factors (e.g., health status, diagnoses) [23]. In this study, however, our data did not capture any enabling factors.

\section{Methods}

\subsection{Study Design and Data Source}

This was a cross-sectional, retrospective study using data from April 1, 2017 to September 30, 2017 from the Electronic Medical Record (EMR) database of the Primary Health Care Corporation (PHCC) in the state of Qatar. $\mathrm{PHCC}$ is a non-profit organization providing primary care to Qatar's entire population. It delivers its services through 23 PHC centers geographically situated across the country based on population densities [31]. These centers are the primary point of contact with Qatar's healthcare system. All healthcare services at these centers are available and accessible to all nationals of Qatar free of charge. Each of these centers serve a population made up of diverse demographic backgrounds such as education, income, ethnicity, and employment representative of Qatar's population [24].

\subsection{Study Population}

The study population comprised all Qatari nationals aged 65 years and over who had medication reconciliation done according to PHCC's established policy. This policy was introduced in January 2017 as a quality assurance measure to reduce any possible medication errors such as wrong or duplicate medication orders, or over/under doses of prescriptions. A multidisciplinary team consisting of primary physicians, nurses, and pharmacists are involved in this process.

\subsection{Data Extraction}

Data were extracted from PHCC's EMR database and included three categories: (1) patient information, including date of birth, gender, and body mass index (BMI); (2) clinical data, including medical diagnoses and listed comorbidities that possibly influence the number of PIM prescriptions; and (3) medications prescribed by attending physicians. The extracted data were validated and de-identified by two medical informatics specialists. Data were initially entered in a specific form designed by the lead investigator (AA), and subsequently coded and entered into the Statistical Package for the Social Sciences (SPSS) program, version 23, for statistical analysis.

\subsection{Data Security}

To ensure confidentiality and privacy of the subjects, all data extracted were completely anonymized by assigning 
unique identifier codes for each. The electronic data were stored on a secure computer with restricted access by the lead investigator.

\subsection{Measures and Definitions}

\subsubsection{Dependent Variables}

The prevalence of PIMs in older adult patients attending PHC centers in Qatar was the dependent variable. The PIMs were identified according to the updated Beers criteria of the American Geriatric Society (AGS) 2015 by applying two of its criteria: (1) medications to avoid for many or most older adults, and (ii) medications to be used with caution (see Supplementary file in the electronic supplementary material [ESM]) [21]. The prevalence of PIM prescription was grouped under these two criteria separately. The prevalence of PIM prescription was further categorized according to the number of PIM prescriptions for each patient in each of Beer's two criteria (i.e., one, two, or three or more PIMs).

\subsubsection{Independent Variables}

Several independent variables were explored in this study based on the Andersen's Behavioral Model. These variables were (1) predisposing factors including age (in years), gender, BMI $\left(\mathrm{kg} / \mathrm{m}^{2}\right)$ and polypharmacy, and (2) needs factors including diabetes mellitus, asthma, dyslipidemia, hypertension, gastrointestinal reflux disease (GERD), cardiovascular diseases (ischemic heart disease, heart failure, arrhythmia, and stroke), arthritis (osteoarthritis and rheumatoid arthritis), and mental health conditions (depression, anxiety and dementia) [25].

We defined polypharmacy as the concurrent use of five or more medications [25]. We coded clinical diagnoses based on the International Classification of Diseases, Tenth Revision, Clinical Modification codes (ICD-10-CM codes) [26]. We recorded and classified the total number of prescribed medications for each patient according to the Anatomical Therapeutic Chemical (ATC) Classification System of the World Health Organization [27]. The fifth level ATC code was used to define the number of prescribed original drug compounds. Dermatological drugs (ATC-class D) and topical products (ATC-class M02) that are less likely to cause drug-related problems (DRP) were excluded.

\subsection{Statistical Analysis}

Descriptive and inferential statistics were used to analyze the data. For continuous variables, means and standard deviations (SDs) were calculated. For categorical variables, frequencies and percentages were used. Bivariate analyses were done with the chi-squared test to examine for differences in characteristics between patients with and without PIM prescriptions. A multivariable logistic regression model was conducted to examine predictors associated with PIMs. Significance level was set at $p$ value $\leq 0.05$ and a $95 \%$ confidence interval (CI). All analyses were performed using SPSS.

\section{Results}

\subsection{Sample Characteristics}

A total of 5639 Qataris aged 65 years and over were identified from the EMRs of the 23 PHC centers and included in the study. The mean age of subjects was $72.8( \pm 6.5)$ years, and $53.8 \%$ were females. About two-thirds $(68.9 \%)$ of the subjects were overweight and obese (BMI $\geq 25)$. Furthermore, the mean number of comorbidities among the subjects was $2.62( \pm 1.14)$. Almost three-quarters of the study subjects $(75.5 \%)$ were exposed to polypharmacy. Table 1 shows the characteristics of the study population.

\subsection{Prevalence and Distribution of Potentially Inappropriate Medications (PIMs)}

The overall prevalence of any PIM prescription in the study sample was 76.0\% (4289/5639). As shown in Table 2, the prevalence of PIMs that should be avoided for many or most older adults was $60.7 \%$ (3422/5639). Most of these patients $(61.1 \%$ [2091/3422]) were prescribed one PIM, $26.9 \%$ (919/3422) were prescribed two PIMs, and 12.0\% (412/3422) were prescribed three or more PIMs. The prevalence of PIMs to be used with caution among older adults was $40.6 \%$ (2291/5639). The majority of these patients (72.7\% [1665/2291] were prescribed one PIM, 21.8\% (499/2291) were prescribed two PIMs, and 5.5\% (127/2291) were prescribed three or more PIMs.

Table 3 shows the distribution of PIM prescriptions in the two 2015 Beers criteria: medications that should be avoided for many or most older adults and medications that should be used with caution. The most commonly prescribed PIMs that should be avoided for many or most older adults were gastrointestinal medications $84.2 \%$ (2881/3422) followed by pain medications $49.9 \%$ (1709/3422). Diuretics $83.1 \%$ (1904/2291) followed by antidepressants 25.7\% (588/2291) were the most prevalent PIMs to be used with caution.

\subsection{Factors Associated with PIMs in Bivariate Analysis}

Table 4 shows the comparison between the characteristics of patients who received prescriptions for PIMs to avoid for many or most older adults and those who didn't receive 
Table 1 Characteristics of Qatari older adults from 23 primary healthcare centers $(N=5639)$

\begin{tabular}{|c|c|}
\hline Variables & Number $(\%)$ \\
\hline \multicolumn{2}{|c|}{ Predisposing characteristics } \\
\hline \multicolumn{2}{|l|}{ Age (years) } \\
\hline $65-69$ & $2200(39.0)$ \\
\hline $70-74$ & $1490(26.4)$ \\
\hline $75-79$ & $1018(18.1)$ \\
\hline $80-84$ & $609(10.8)$ \\
\hline 85 or more & $322(5.7)$ \\
\hline \multicolumn{2}{|l|}{ Gender } \\
\hline Female & $3035(53.8)$ \\
\hline Male & $2604(46.2)$ \\
\hline \multicolumn{2}{|l|}{ Body mass index $\left(\mathrm{kg} / \mathrm{m}^{2}\right)$} \\
\hline Underweight $(<18.5)$ & $90(1.6)$ \\
\hline Normal (18.5-24.9) & $605(10.7)$ \\
\hline Overweight (25-29.9) & $1441(25.6)$ \\
\hline Obese $(\geq 30)$ & $2441(43.3)$ \\
\hline Missing & $1062(18.8)$ \\
\hline \multicolumn{2}{|l|}{ Needs characteristics } \\
\hline \multicolumn{2}{|c|}{ Number of chronic health conditions } \\
\hline 0 & $244(4.3)$ \\
\hline 1 & $744(13.2)$ \\
\hline 2 & $1461(25.9)$ \\
\hline $3+$ & $3182(56.4)$ \\
\hline \multicolumn{2}{|c|}{ Polypharmacy status (use of $\geq 5$ medications) } \\
\hline Yes & $4257(75.5)$ \\
\hline No & $1382(24.5)$ \\
\hline \multicolumn{2}{|l|}{ Hypertension } \\
\hline Yes & $4651(81.8)$ \\
\hline No & $1023(18.2)$ \\
\hline \multicolumn{2}{|l|}{ Diabetes mellitus } \\
\hline Yes & $4176(74.1)$ \\
\hline No & $1463(25.9)$ \\
\hline \multicolumn{2}{|l|}{ Dyslipidemia } \\
\hline Yes & $2445(43.4)$ \\
\hline No & $3194(56.6)$ \\
\hline \multicolumn{2}{|l|}{ Cardiovascular disease $^{\mathrm{a}}$} \\
\hline Yes & $1169(20.7)$ \\
\hline No & $4470(79.3)$ \\
\hline \multicolumn{2}{|l|}{ Asthma } \\
\hline Yes & $1152(20.4)$ \\
\hline No & 4486 (79.6) \\
\hline \multicolumn{2}{|l|}{ Arthritis ${ }^{\mathrm{b}}$} \\
\hline Yes & $1033(18.3)$ \\
\hline No & $4606(81.7)$ \\
\hline \multicolumn{2}{|c|}{ Gastroesophageal reflux disease } \\
\hline Yes & 708 (12.6) \\
\hline No & 4931 (87.4) \\
\hline \multicolumn{2}{|l|}{ Mental disorders ${ }^{\mathrm{c}}$} \\
\hline Yes & $177(3.1)$ \\
\hline No & 5462 (96.9) \\
\hline
\end{tabular}

${ }^{a}$ Ischemic heart disease, heart failure, arrhythmia, and stroke

${ }^{\mathrm{b}}$ Osteoarthritis and rheumatoid arthritis

${ }^{c}$ Depression, anxiety, and dementia them. The prevalence of PIMs was significantly higher in females than males $(64.6 \%$ vs $56.1 \% ; p<0.001)$. Also, the prescription of PIMs was significantly higher in patients who were exposed to polypharmacy compared with those who were not $(70.7 \%$ vs $28.8 ; p<0.001)$. Moreover, patients who had chronic conditions including diabetes, hypertension, cardiovascular disease, dyslipidemia, asthma, mental disorders, GERD, and arthritis compared with those without these comorbidities were all significantly associated with PIM prescription.

All factors tested in the bivariate analysis were included in the logistic regression analysis except for the "number of chronic health conditions' variable because it has collinearity with the health conditions included in the model. Adjusted odds ratios (AOR) and 95\% confidence intervals (CIs) for predictors of PIMs to avoid for many or most older adults are shown in Table 5. Older patients with polypharmacy were more than six times more likely to have PIM prescriptions compared with those without polypharmacy (AOR 6.54; 95\% CI 5.64-7.59). In addition, PIM prescription was more likely among females compared with males (AOR 1.39; 95\% CI 1.23-1.56). Finally, diabetes mellitus (AOR 1.46; 95\% CI 1.26-1.70), hypertension (AOR 1.21; 95\% CI 1.02-1.42), cardiovascular diseases (AOR 1.38; 95\% CI 1.18-1.60), asthma (AOR 1.21; 95\% CI 1.04-1.41), GERD (AOR 2.99; 95\% CI 2.43-3.69), and arthritis (AOR $1.30 ; 95 \%$ CI 1.11-1.52) were found to be significant predictors of PIM prescription.

\section{Discussion}

This was a cross-sectional, retrospective study of older adult outpatients attending PHC centers in Qatar to determine the prevalence and predictors of PIM prescription. The dependent variable in this study was PIM prescription and the independent variables were predisposing and need factors according to the Andersen Behavior Model. To the best of our knowledge, this is the first study in Qatar that investigated PIM prescriptions in older adult outpatients according to the 2015 Beers criteria. A previous study in Qatar by Alhmoud et al. [11] had used the 2012 Beers criteria and involved a small sample of patients $(N=501)$ who received specialized home health care services in comparison with our study population.

Results in our study showed a high prevalence of PIM prescription $(76.0 \%)$. Other studies in the Middle East have reported varying prevalence rates: in Qatar 38.2\% [11] and in Jordan $62.5 \%$ [9]. Our study showed a very high prevalence of prescribed PIMs with $60.7 \%(n=3422)$ in the should be avoided and $40.6 \%(n=2291)$ in the should be used with caution categories. The prevalence rates reported in other studies varied. For instance, in 
Table 2 Prevalence of PIM prescriptions among Qatari older adults according to 2015 Beers criteria $(N=5639)$

\begin{tabular}{|c|c|c|c|c|c|c|}
\hline & \multicolumn{3}{|c|}{$\begin{array}{l}\text { PIMs to avoid for many or most older } \\
\text { adults }\end{array}$} & \multicolumn{3}{|c|}{ PIMs to be used with caution } \\
\hline & $n$ & $\%$ & $95 \% \mathrm{CI}$ & $n$ & $\%$ & $95 \% \mathrm{CI}$ \\
\hline PIM use & 3422 & 60.7 & $59.4-61.6$ & 2291 & 40.6 & $39.3-41.9$ \\
\hline \multicolumn{7}{|l|}{ Number of PIMs used } \\
\hline One PIM & 2091 & 61.1 & $59.4-62.7$ & 1665 & 72.7 & $70.8-74.5$ \\
\hline Two PIMs & 919 & 26.9 & $25.4-28.4$ & 499 & 21.8 & $20.1-23.5$ \\
\hline Three or more PIMs & 412 & 12.0 & $11.0-13.2$ & 127 & 5.5 & $4.6-6.7$ \\
\hline
\end{tabular}

PIM potentially inappropriate medication the study in Qatar by Alhmoud and associates [11], the prevalence of PIMs that should be avoided was $35.0 \%$ and those that should be used with caution was $56.0 \%$. In another cross-sectional retrospective study in Saudi Arabia of 4073 older adults in an ambulatory care setting of a large tertiary hospital, Alhawassi et al. [10] showed the prevalence of PIMs that should be avoided was $57.5 \%$ and those that should be used with caution was $37.5 \%$. Also, in another cross-sectional study in Jordan involving 4622 older adult outpatients, Al-Azayzih et al. [9] reported $62.5 \%(n=2891)$ of patients had at least one PIM prescribed. Of these outpatients, 69.0\% $(n=1995)$ had prescriptions of PIMs to be used with caution [9]. Finally, in a very large population study of 523,811 older adults in Korea, You-Seon et al. [17] applied the Beers 2012 criteria (medications to be avoided for most older adults and medications to be avoided for certain diseases or syndromes) and reported that $80.96 \%$ of their subjects were prescribed at least one PIM regardless of their diagnosis or health condition [17].

The most common classes of PIM prescription in our study were gastrointestinal (84.2\%) followed by pain medications (49.9\%), compared with the Saudi Arabia study where $35.6 \%$ of the PIMs were gastrointestinal agents followed by $34.3 \%$ endocrine agents [10]. In the home care population study in Qatar, the two leading classes of PIMs were antipsychotics (27.4\%) and selective serotonin reuptake inhibitors (16.0\%) [11]. Other studies have reported different classes of PIM drugs such as nonsteroidal anti-inflammatory drugs $[2,28]$ and antidepressants, antipsychotics, and benzodiazepines [28-30]. The differences in the reported PIM prescription prevalence rates and medication classes may be related to different study populations in different settings, study designs, and versions and criteria of the Beers tool used.

Consistent with other studies, the multivariable logistic regression showed female gender to be significantly associated with PIM prescription [9, 17]. A possible reason for this may be that females are at a higher risk of developing chronic conditions [31, 32], which may lead to more inappropriate prescribing. Other significant predictors of PIM prescription our study identified were the presence of polypharmacy, diabetes mellitus, hypertension, cardiovascular diseases, asthma, GERD, and arthritis. Other studies have also shown similar predictors [6, 9-11]. A surprising finding was that age was not a significant predictor. As the prevalence of chronic morbidity increases with age, so does the risk of multiple comorbidities [31]. Multiple comorbidities potentially increase PIM prescriptions, which may lead to adverse events in older adults [33, 34]. However, the association of age with PIM prescriptions has been inconsistently reported across studies [1].

\subsection{Strengths and Limitations}

Our study had several strengths. We used a very large sample of older adults attending PHC centers in Qatar and highlighted the high prevalence of PIM prescription, which is associated with potentially serious negative outcomes in this population. While the study subjects were not a representative sample, our study allowed for the depiction of the magnitude of the practice of PIM prescription by physicians. Furthermore, using EMR records facilitated the retrieval of accurate data and avoided potential recall and selection biases.

While our study had several strengths, it also had a few limitations that need to be highlighted. For one, our study used a cross-sectional, retrospective design, which prevents the establishment of causal relationships between the dependent and independent variables. Second, the study design and the availability of EMR data restricted us to the use of only two of the 2015 Beers criteria. Application of the five criteria would have given us a more comprehensive profile of the PIM prescriptions. Third, while we captured the prevalence of PIM prescriptions, we did not confirm their actual consumption by patients. Non-adherence to prescribed medications is a common occurrence in clinical practice [35].

Regarding the Andersen's Behavioral Model, our data had age, gender, and BMI as predisposing characteristics 
Table 3 Distribution of classes of PIM prescriptions among 5639 Qatari older adults according to 2015 Beers criteria

\begin{tabular}{|c|c|}
\hline Medication group/class & $n(\%)$ \\
\hline \multicolumn{2}{|c|}{ Medications to avoid for many or most older adults $(N=3422)$} \\
\hline Gastrointestinal & $2881(84.2)$ \\
\hline Proton pump inhibitors & $2843(83.0)$ \\
\hline Metoclopramide & $38(1.1)$ \\
\hline Pain medications & $1709(49.9)$ \\
\hline Orphenadrine & $1020(29.8)$ \\
\hline Non-COX-Selective NSAIDs & $689(20.1)$ \\
\hline Central nervous system & $355(10.4)$ \\
\hline Antidepressants & $137(4.0)$ \\
\hline Antipsychotics & $190(5.5)$ \\
\hline Benzodiazepines & $28(0.8)$ \\
\hline Cardiovascular & $214(6.2)$ \\
\hline Nifedipine IR & $139(4.0)$ \\
\hline Amiodarone & $28(0.8)$ \\
\hline Digoxin & $26(0.7)$ \\
\hline Central $\alpha$-blockers & $13(0.4)$ \\
\hline Peripheral $\alpha$-blockers & $8(0.2)$ \\
\hline Antispasmodics & $72(2.1)$ \\
\hline Anticholinergics (1st generation antihistamines) & $64(1.9)$ \\
\hline Anti-infective (nitrofurantoin) & $27(0.8)$ \\
\hline Endocrine & $12(0.3)$ \\
\hline \multicolumn{2}{|l|}{ Medications to be used with caution $(N=2291)$} \\
\hline Diuretics & $1904(83.1)$ \\
\hline Antidepressants & $588(25.7)$ \\
\hline SSRIs & $223(9.7)$ \\
\hline TCAs & $125(5.5)$ \\
\hline SNRIs & $165(7.2)$ \\
\hline Mirtazapine & $75(3.3)$ \\
\hline Antiplatelet/anticoagulants & $420(18.3)$ \\
\hline Aspirin (prevention of cardiac events) ${ }^{\mathrm{a}}$ & $412(18.0)$ \\
\hline Dabigatran $^{\mathrm{b}}$ & $8(0.3)$ \\
\hline Antipsychotics & $190(8.3)$ \\
\hline Vasodilators & $90(3.9)$ \\
\hline Anticonvulsants (carbamazepine) & $37(1.6)$ \\
\hline
\end{tabular}

COX cyclooxygenase, IR immediate release, NSAIDs non-steroidal anti-inflammatory drugs, PIM potentially inappropriate medication, SNRIs serotonin and norepinephrine reuptake inhibitors, SSRIs selective serotonin reuptake inhibitors, TCAs tricyclic antidepressants

${ }^{\text {a }}$ Used in adults aged $\geq 80$ years old

${ }^{\mathrm{b}}$ Used in adults aged $\geq 75$ years old

and several need characteristics, but no enabling ones. We recommend that in future studies in Qatar, a more fulsome spectrum of data is collected to better explain findings in accordance with the Andersen's Behavioral Model.

\subsection{Implications for Clinical Practice, Policy, and Research}

The high prevalence of PIMs and their demonstrated negative outcomes in older adults highlights several important implications for clinicians, researchers, and policy makers. An essential practice should be communication and information transfer between clinicians, especially in primary care settings where patients are seen by any number of physicians. Another implication for clinicians should be the periodic critical review of prescribed medications and their continued necessity in the therapeutic management of patients. Policy makers and the leadership in PHC centers should develop best practice guidelines for clinicians for prescribing and critical medication reconciliation. There should also be corresponding mechanisms for auditing and reviewing clinicians' prescribing practices.

In our study we focused on prevalence of PIMs, types of medications, and patient factors. It would be essential to also study clinician factors. Research has shown several factors that influence clinicians' prescribing practices [36]. Such research in Qatar's PHCs would provide useful data to inform policy and best practice guidelines development.

\section{Conclusions}

Our study showed that in older adult patients attending Qatar's 23 PHC centers, a large number of PIMs are prescribed that should be avoided or used with caution. Logistic regression showed female gender, polypharmacy, and certain comorbidities were significantly associated with PIM prescription. The most prevalent classes of PIM prescription that should be avoided included gastrointestinal, pain, central nervous system, and cardiovascular disease drugs, while the should be used with caution category included diuretics, antidepressants, antiplatelets, and antipsychotics. With growth in the proportion of older adults in Qatar and the high risk of PIM prescription, the practice of medication reconciliation by primary care physicians should be strengthened and reinforced. Future studies should study PIM prescription in prospective cohorts to explore the occurrence of negative outcomes in this vulnerable population of older adults. 
Table 4 Comparison of patient characteristics between those who were prescribed PIMs to avoid for many or most older adults or not prescribed PIMs

\begin{tabular}{|c|c|c|c|}
\hline Variable & $\begin{array}{l}\text { PIM prescriptions } \\
(n=3422) \\
\text { Count }(\%)\end{array}$ & $\begin{array}{l}\text { No PIM prescriptions } \\
(n=2217) \\
\text { Count }(\%)\end{array}$ & $p$ value \\
\hline Age (years) & & & 0.357 \\
\hline $65-69$ & $1314(59.7)$ & $886(40.3)$ & \\
\hline $70-74$ & $925(62.1)$ & $565(37.9)$ & \\
\hline $75-79$ & $606(59.5)$ & $412(40.5)$ & \\
\hline $80-84$ & $380(62.4)$ & $229(37.6)$ & \\
\hline $85+$ & $197(61.2)$ & $125(38.8)$ & \\
\hline Gender & & & $<0.001$ \\
\hline Male & $1461(56.1)$ & $1143(43.9)$ & \\
\hline Female & $1961(64.6)$ & $1074(35.4)$ & \\
\hline Body mass index $\left(\mathrm{kg} / \mathrm{m}^{2}\right)$ & & & $<0.001$ \\
\hline Underweight $(<18.5)$ & $53(58.9)$ & $37(41.1)$ & \\
\hline Normal (18.5-24.9) & $362(59.8)$ & $243(40.2)$ & \\
\hline Overweight (25-29.9) & $856(59.4)$ & $585(40.6)$ & \\
\hline Obese $(\geq 30)$ & $1591(65.2)$ & $850(3.8)$ & \\
\hline Number of chronic health conditions & & & $<0.001$ \\
\hline 1 & $374(50.3)$ & 370 (49.7) & \\
\hline 2 & $803(55.0)$ & $658(45.0)$ & \\
\hline 3 & $970(60.2)$ & $640(39.8)$ & \\
\hline $4+$ & $1136(72.3)$ & $436(27.7)$ & \\
\hline Polypharmacy status & & & $<0.001$ \\
\hline No & $412(28.8)$ & $970(70.2)$ & \\
\hline Yes & $3010(70.7)$ & $1247(29.3)$ & \\
\hline Diabetes mellitus & & & 0.004 \\
\hline No & $845(57.8)$ & $618(42.2)$ & \\
\hline Yes & $2577(61.7)$ & $1599(38.3)$ & \\
\hline Hypertension & & & $<0.001$ \\
\hline No & $564(55.1)$ & 459 (44.9) & \\
\hline Yes & $2857(61.9)$ & $1758(38.1)$ & \\
\hline Cardiovascular disease & & & $<0.001$ \\
\hline No & 2618 (58.6) & $1852(41.4)$ & \\
\hline Yes & $804(68.8)$ & 365 (31.2) & \\
\hline Dyslipidemia & & & 0.001 \\
\hline No & $1882(58.9)$ & $1312(41.1)$ & \\
\hline Yes & $1540(63.0)$ & $905(37.0)$ & \\
\hline Asthma & & & $<0.001$ \\
\hline No & $2633(58.7)$ & $1835(41.3)$ & \\
\hline Yes & $788(68.4)$ & $364(31.6)$ & \\
\hline Mental disorders & & & 0.003 \\
\hline No & $3297(60.4)$ & 2165 (39.6) & \\
\hline Yes & $125(70.6)$ & $52(29.4)$ & \\
\hline Gastroesophageal reflux disease & & & $<0.001$ \\
\hline No & $2856(57.9)$ & 2075 (42.1) & \\
\hline Yes & $566(79.9)$ & $142(20.1)$ & \\
\hline Arthritis & & & $<0.001$ \\
\hline No & $2725(59.2)$ & $1881(40.8)$ & \\
\hline Yes & 697 (67.5) & $336(32.5)$ & \\
\hline
\end{tabular}

PIM potentially inappropriate medication 
Table 5 Predictors of PIM prescription that should be avoided for most older adults according to Beers 2015 criteria

\begin{tabular}{|c|c|c|}
\hline Variable & Adjusted OR (95\% CI) & $p$ value \\
\hline \multicolumn{3}{|c|}{ Predisposing characteristics } \\
\hline \multicolumn{3}{|l|}{ Age (years) } \\
\hline $65-69$ & Reference & 0.942 \\
\hline $70-74$ & $1.02(0.88-1.18)$ & 0.870 \\
\hline $75-79$ & $0.95(0.80-1.12)$ & 0.763 \\
\hline $80-84$ & $1.05(0.86-1.29)$ & 0.098 \\
\hline $85+$ & $1.10(0.85-1.44)$ & 0.942 \\
\hline \multicolumn{3}{|l|}{ Gender } \\
\hline Male & Reference & \\
\hline Female & $1.39(1.23-1.56)$ & $<0.001 *$ \\
\hline \multicolumn{3}{|l|}{ Body mass index $\left(\mathrm{kg} / \mathrm{m}^{2}\right)$} \\
\hline Underweight $(<18.5)$ & Reference & \\
\hline Normal (18.5-24.9) & $1.08(0.62-1.89)$ & 0.797 \\
\hline Overweight (25-29.9) & $0.97(0.56-1.66)$ & 0.995 \\
\hline Obese $(\geq 30)$ & $1.09(0.64-1.87)$ & 0.504 \\
\hline \multicolumn{3}{|l|}{ Polypharmacy status } \\
\hline No & Reference & \\
\hline Yes & $6.54(5.64-7.59)$ & $<0.001^{*}$ \\
\hline \multicolumn{3}{|l|}{ Need characteristics } \\
\hline \multicolumn{3}{|l|}{ Diabetes mellitus } \\
\hline No & Reference & \\
\hline Yes & $1.46(1.26-1.70)$ & $<0.001 *$ \\
\hline \multicolumn{3}{|l|}{ Hypertension } \\
\hline No & Reference & \\
\hline Yes & $1.21(1.02-1.42)$ & $0.023 *$ \\
\hline \multicolumn{3}{|l|}{ Cardiovascular disease } \\
\hline No & Reference & \\
\hline Yes & $1.38(1.18-1.60)$ & $<0.001 *$ \\
\hline \multicolumn{3}{|l|}{ Dyslipidemia } \\
\hline No & Reference & \\
\hline Yes & $0.89(0.79-1.01)$ & 0.085 \\
\hline \multicolumn{3}{|l|}{ Asthma } \\
\hline No & Reference & \\
\hline Yes & $1.21(1.04-1.41)$ & $0.011 *$ \\
\hline \multicolumn{3}{|l|}{ Mental disorders } \\
\hline No & Reference & \\
\hline Yes & $1.24(0.86-1.78)$ & 0.243 \\
\hline \multicolumn{3}{|c|}{ Gastroesophageal reflux disease } \\
\hline No & Reference & \\
\hline Yes & $2.99(2.43-3.69)$ & $<0.001 *$ \\
\hline \multicolumn{3}{|l|}{ Arthritis } \\
\hline No & Reference & \\
\hline Yes & $1.30(1.11-1.52)$ & $0.001 *$ \\
\hline
\end{tabular}

PIM potentially inappropriate medication

*Statistically significant

\section{Declarations}

Funding Open Access funding provided by the Qatar National Library.

Conflict of interest Ayman Al-Dahshan and Vahe Kehyayan have no conflicts of interest that are directly relevant to the content of this study.

Ethics approval This study received ethical approval from PHCC's Independent Ethics Committee (PHCC-IEC; reference number PHCC/ $\mathrm{RS} / 17 / 11 / 015)$. The IEC waved the requirement for informed consents because all patients' data were retrieved anonymously.

Consent to participate All data retrieved from the electronic medical records were de-identified.

Consent for publication The authors consent.

Availability of data and material The datasets generated and analyzed during the current study are available from the corresponding author on reasonable request.

Code availability Not applicable.

Authors' contributions AAD conceived and designed the study, obtained ethics approval, and generated and analyzed the data. AAD and VK drafted the manuscript. AAD helped with the interpretation of the data and discussion. VK critically reviewed and edited the manuscript.

Open Access This article is licensed under a Creative Commons Attribution-NonCommercial 4.0 International License, which permits any non-commercial use, sharing, adaptation, distribution and reproduction in any medium or format, as long as you give appropriate credit to the original author(s) and the source, provide a link to the Creative Commons licence, and indicate if changes were made. The images or other third party material in this article are included in the article's Creative Commons licence, unless indicated otherwise in a credit line to the material. If material is not included in the article's Creative Commons licence and your intended use is not permitted by statutory regulation or exceeds the permitted use, you will need to obtain permission directly from the copyright holder. To view a copy of this licence, visit http://creativecommons.org/licenses/by-nc/4.0/.

\section{References}

1. Nothelle SK, Sharma R, Oakes A, Jackson M, Segal JB. Factors associated with potentially inappropriate medication use in community-dwelling older adults in the United States: a systematic review. Int J Pharm Pract. 2019;27(5):408-23.

2. Davidoff AJ, Miller GE, Sarpong EM, Yang E, Brandt N, Fick DM. Prevalence of potentially inappropriate medication use in older adults using the 2012 Beers criteria. J Am Geriatr Soc. 2015;63(3):486-500.

3. Alkan A, Yaşar A, Karcı E, Köksoy E, Ürün M, Şenler F, et al. Severe drug interactions and potentially inappropriate medication usage in elderly cancer patients. Support Care Cancer. 2017;25(1):229-36.

4. Blanco-Reina E, Valdellós J, Aguilar-Cano L, García-Merino MR, Ocaña-Riola R, Ariza-Zafra G, et al. 2015 Beers criteria and STOPP v2 for detecting potentially inappropriate medication 
in community-dwelling older people: prevalence, profile, and risk factors. Eur J Clin Pharmacol. 2019;75(10):1459-66.

5. Hudhra K, García-Caballos M, Casado-Fernandez E, Jucja B, Shabani D, Bueno-Cavanillas A. Polypharmacy and potentially inappropriate prescriptions identified by Beers and STOPP criteria in co-morbid older patients at hospital discharge. J Eval Clin Pract. 2016;22(2):189-93.

6. Vieira DL, Garbin CAS, Garbin AJI, Sumida D, Saliba O. Potentially inappropriate medications used by the elderly: prevalence and risk factors in Brazilian care homes. BMC Geriatr. 2013;13(1):52-52.

7. Sönnerstam E, Sjölander M, Gustafsson M. An evaluation of the prevalence of potentially inappropriate medications in older people with cognitive impairment living in Northern Sweden using the EU(7)-PIM list. Eur J Clin Pharmacol. 2017;73(6):735-42.

8. Ryan C, O'Mahony D, Kennedy J, Weedle P, Byrne S. Potentially inappropriate prescribing in an Irish elderly population in primary care. Br J Clin Pharmacol. 2009;68(6):936-47.

9. Al-Azayzih A, Alamoori R, AlTawalbeh SM. Potentially inappropriate medications prescribing according to Beers criteria among elderly outpatients in Jordan: a cross sectional study. Pharm Pract. 2019;17(2):1-7.

10. Alhawassi TM, Alatawi W, Alwhaibi M. Prevalence of potentially inappropriate medications use among older adults and risk factors using the 2015 American Geriatrics Society Beers criteria. BMC Geriatr. 2019;19(1):1-8.

11. Alhmoud E, Khalifa S, Bahi A, Bahi AA. Prevalence and predictors of potentially inappropriate medications among home care elderly patients in Qatar. Int J Clin Pharm. 2015;37(5):815-21.

12. Bahlas SM, Anshasi NW, Alqurashi SH, Elhosiny AA, Kamal EK, Andijani RA. Evaluating potentially inappropriate medications in the elderly population at KAUH, Jeddah, KSA. Int J Adv Res (IJAR). 2017;5(11):540-5.

13. Saab YB, Hachem A, Sinno S, El-Moalem H. Inappropriate medication use in elderly Lebanese outpatients: prevalence and risk factors. Drugs Aging. 2006;23(9):743-52.

14. Motter FR, Fritzen JS, Hilmer SN, Paniz ÉV, Paniz VMV. Potentially inappropriate medication in the elderly: a systematic review of validated explicit criteria. Eur J Clin Pharmacol. 2018;74(6):679-700.

15. Grina D, Briedis V. The use of potentially inappropriate medications among the Lithuanian elderly according to Beers and EU(7)PIM list-a nationwide cross-sectional study on reimbursement claims data. J Clin Pharm Ther. 2017;42(2):195-200.

16. Morin L, Laroche M, Texier G, Johnell K. Prevalence of potentially inappropriate medication use in older adults living in nursing homes: a systematic review. J Am Med Dir Assoc. 2016;17(9):862.e1-862.e9.

17. You-Seon N, Jong SH, Ju YK, Woo KB, Lee K, Nam Y, et al. Prescription of potentially inappropriate medication in Korean older adults based on 2012 Beers Criteria: a cross-sectional population based study. BMC Geriatr. 2016;16:1-9.

18. Hyttinen V, Jyrkkä J, Saastamoinen LK, Vartiainen A, Valtonen H. Patient- and health care-related factors associated with initiation of potentially inappropriate medication in community-dwelling older persons. Basic Clin Pharmacol Toxicol. 2019;124(1):74-83.

19. Bolina AF, Gomes NC, Marchiori GF, Pegorari MS, Tavares DMDS. Potentially inappropriate medication use and frailty phenotype among community-dwelling older adults: a populationbased study. J Clin Nurs. 2019;28(21):3914-22.

20. Muhlack DC, Hoppe LK, Stock C, Haefeli WE, Brenner H, Schöttker B. The associations of geriatric syndromes and other patient characteristics with the current and future use of potentially inappropriate medications in a large cohort study. Eur J Clin Pharmacol. 2018;74(12):1633-44.
21. Fick DM, Semla TP, Steinman M, Beizer J, Brandt N, Dombrowski R, et al. American Geriatrics Society 2019 updated AGS Beers Criteria $^{\circledR}$ for potentially inappropriate medication use in older adults. J Am Geriatr Soc. 2019;67(4):674-94.

22. Kachru N, Carnahan R, Johnson M, Aparasu R. Potentially inappropriate anticholinergic medication use in community-dwelling older adults: a national cross-sectional study. Drugs Aging. 2015;32(5):379-89.

23. Andersen R, Newman JF. Societal and individual determinants of medical care utilization in the United States Milbank Memorial Fund Quarterly-Health \& Society. Winter. 1973;51(1):95-124.

24. Primary Health Care Corporation. National Primary Health Care Strategy 2013-2018: Building the Foundation. 2013; https://www. google.com/search?q=National+Primary+Health+Care+Strat egy $+2013-2018 \% 3 \mathrm{~A}+$ Building + the + Foundation $\&$ oq $=$ Natio nal+Primary+Health+Care+Strategy+2013-2018\%3A+Build ing + the + Foundation $\&$ aqs $=$ chrome $.69 i 57.1660 j 0 j 8 \&$ sourc eid $=$ chrome \&ie $=U T F-8$. Accessed 1 May 2020.

25. Masnoon N, Shakib S, Kalisch-Ellett L, Caughey GE. What is polypharmacy? A systematic review of definitions. BMC Geriatr. 2017;17:1-10.

26. World Health Organization. ICD-10: International Statistical Classification of Diseases and Related Health Problems, 10th Revision, vol 3, 2nd edn. Geneva: World Health Organization; 2016.

27. World Health Organization. Anatomical Therapeutic Chemical (ATC) Classification System. 2003. https://www.who.int/classifica tions/atcddd/en/. Accessed 11 Jan 2020.

28. Nishtala PS, Bagge ML, Campbell AJ, Tordoff JM. Potentially inappropriate medicines in a cohort of community-dwelling older people in New Zealand. Geriatr Gerontol Int. 2014;14(1):89-93.

29. Barnett K, McCowan C, Evans JMM, Gillespie ND, Davey PG, Fahey T. Prevalence and outcomes of use of potentially inappropriate medicines in older people: cohort study stratified by residence in nursing home or in the community. BMJ Qual Saf. 2011;20(3):275-81

30. Suzuki Y, Sakakibara M, Shiraishi N, Hirose T, Akishita M, Kuzuya M. Prescription of potentially inappropriate medications to older adults. A nationwide survey at dispensing pharmacies in Japan. Arch Gerontol Geriatr. 2018;77:8-12.

31. Fabbri E, Zoli M, Gonzalez-Freire M, Salive ME, Studenski SA, Ferrucci L. Aging and multimorbidity: new tasks, priorities, and frontiers for integrated gerontological and clinical research. J Am Med Dir Assoc. 2015;16(8):640-7.

32. van den Akker M, Buntinx F, Metsemakers JF, Roos S, Knottnerus JA. Multimorbidity in general practice: prevalence, incidence, and determinants of co-occurring chronic and recurrent diseases. J Clin Epidemiol. 1998;51(5):367-75.

33. Hagstrom K, Nailor M, Lindberg M, Hobbs L, Sobieraj DM. Association between potentially inappropriate medication use in elderly adults and hospital-related outcomes. J Am Geriatr Soc. 2015;63(1):185-6.

34. Wang T, Ku P, Lu H, Hsu K, Trezise D, Wang H. Association between potentially inappropriate medication use and chronic diseases in the elderly. Int J Environ Res Public Health. 2019;16(12):06-20.

35. Lee S, Raamkumar AS, Li J, Cao Y, Witedwittayanusat K, Chen $\mathrm{L}$, et al. Reasons for primary medication nonadherence: a systematic review and metric analysis. J Manag Care Specialty Pharm. 2018;24(8):778-94.

36. Cullinan S, O'Mahony D, Fleming A, Byrne S. A meta-synthesis of potentially inappropriate prescribing in older patients. Drugs Aging. 2014;31(8):631-8. 